\section{First three-dimensional tracks of bat migration reveal large amounts of individual behavioral flexibility}

\author{
M. Teague O’Mara, ${ }^{1,2,3,5}$ Martin Wikelski, ${ }^{1,2}$ Bart \\ Kranstauber $^{1,4}$, And Dina K. N. Dechmann ${ }^{1,2}$ \\ Manuscript received 16 January 2019; revised 8 April 2019; \\ accepted 25 April 2019. Corresponding Editor: John Pastor. \\ ${ }^{1}$ Department of Migration, Max Planck Institute of Animal \\ Behavior, Am Obstberg 1, Radolfzell, 78315 Germany. \\ ${ }^{2}$ Department of Biology, University of Konstanz, \\ Universitätstr. 10, Konstanz, 78457 Germany. \\ ${ }^{3}$ Centre for the Advanced Study of Collective Behaviour, \\ University of Konstanz, Universitätstr. 10, Konstanz, 78457 \\ Germany. \\ ${ }^{4}$ Department of Evolutionary Biology and Environmental \\ Studies, University of Zurich, Winterthurstr. 190, Zurich, 8057 \\ Switzerland. \\ ${ }^{4}$ E-mail: tomara@orn.mpg.de
}

Citation: O'Mara, M. T., M. Wikelski, B. Kranstauber, and D. K. N. Dechmann. 2019. First three-dimensional tracks of bat migration reveal large amounts of individual behavioral flexibility. Ecology 100(9):e02762. 10.1002/ecy. 2762

Key words: aeroecology; altitude; common noctule; flight; Grosser Abendsegler; migration; movement; movement ecology; Nyctalus noctula; radio tracking.

Animal migration has fascinated humans at least since Aristotle's time, but we only started to understand its details thanks to the famous "arrow storks" in the 19th century that returned to Europe with arrows in their bodies, providing the first clues of African wintering sites. Bird migration has received a large amount of attention since then, but knowledge about migration of other organisms, even small passerine birds, remains rudimentary (Bowlin et al. 2010).

It is generally assumed that small migrating birds and bats explore wind conditions and then choose a flight altitude, which they then maintain (Bowlin et al. 2010). However, tracking of individual animals highlights this may not be the norm. Migrating thrushes, for example, undergo multiple unexplained changes in flight altitude (Bowlin et al. 2015), and bar-headed geese follow the topographic relief of the Himalayas (Bishop et al. 2015). This variation in flight strategies may be caused by the complex decisions individuals make relative to their environment to minimize costs. Because of their high metabolism and flight costs, bats should also minimize energy expenditure during migratory flight, but we know little of how individuals make their migratory journeys. In Europe, only 4 of 45 species migrate more than $1,000 \mathrm{~km}$ (Hutterer 2005). These nocturnal, echolocating mammals have a unique perspective on the landscape (Fig. 1), but detailed knowledge on individual migration is scarce (Krauel and McCracken 2013). This is alarming, as insectivorous bats are not only important pest control agents, but many are threatened or endangered, particularly migratory species (available online) ${ }^{5}$

Efforts to understand temperate-zone bat migration have begun to show departure conditions (Dechmann et al. 2017), orientation/navigation (Holland 2007), and physiology (e.g., McGuire et al. 2014) of their migration. Nevertheless, most of what we know about individual migration movements stems from ring recoveries (Hutterer 2005; but see Weller et al. 2016). These data resemble those first arrow storks - two points in time, limiting knowledge about migration step length, landscape use, stopover site requirements, and three-dimensional space. Documenting individual migration altitudes is particularly important because of increasing densities of wind power turbines - a major cause of migrating bat mortality (Voigt et al. 2012). Suitable GPS devices for these small animals have only recently been developed, are still relatively heavy, and require relocating the logger. This necessitates additional approaches to study individual three-dimensional movement.

Ring recoveries of the common noctule (Nyctalus noctula, Fig. 1) show that they migrate up to $1,546 \mathrm{~km}$ (Hutterer 2005). Both sexes hibernate at lower latitudes, such as our study site in southern Germany and Switzerland $\left(47.65270^{\circ} \mathrm{N}, 9.18546^{\circ} \mathrm{E}, 395 \mathrm{~m}\right.$ above sea level; Fig. 2). Migration direction is consistent within local populations (Häussler and Nagel 2003, Hutterer 2005); for example, bats from Lake Constance migrate northeast in the spring and return in the autumn (Dechmann et al. 2014).

Development of miniaturized barometric pressure radio transmitters (Sparrow Systems, Fisher, IL, USA) encouraged us to follow the three-dimensional paths of migrating noctules (Bowlin et al. 2015). We removed bats from their boxes during the spring migration period (April 25-May 5), and tagged them using a collar attachment (Fig. 1; O'Mara et al. 2014). Transmitter mass was within $5 \%$ of body mass. MW flew above each

\footnotetext{
${ }^{5}$ https://www.cms.int/en/convention-text
} 


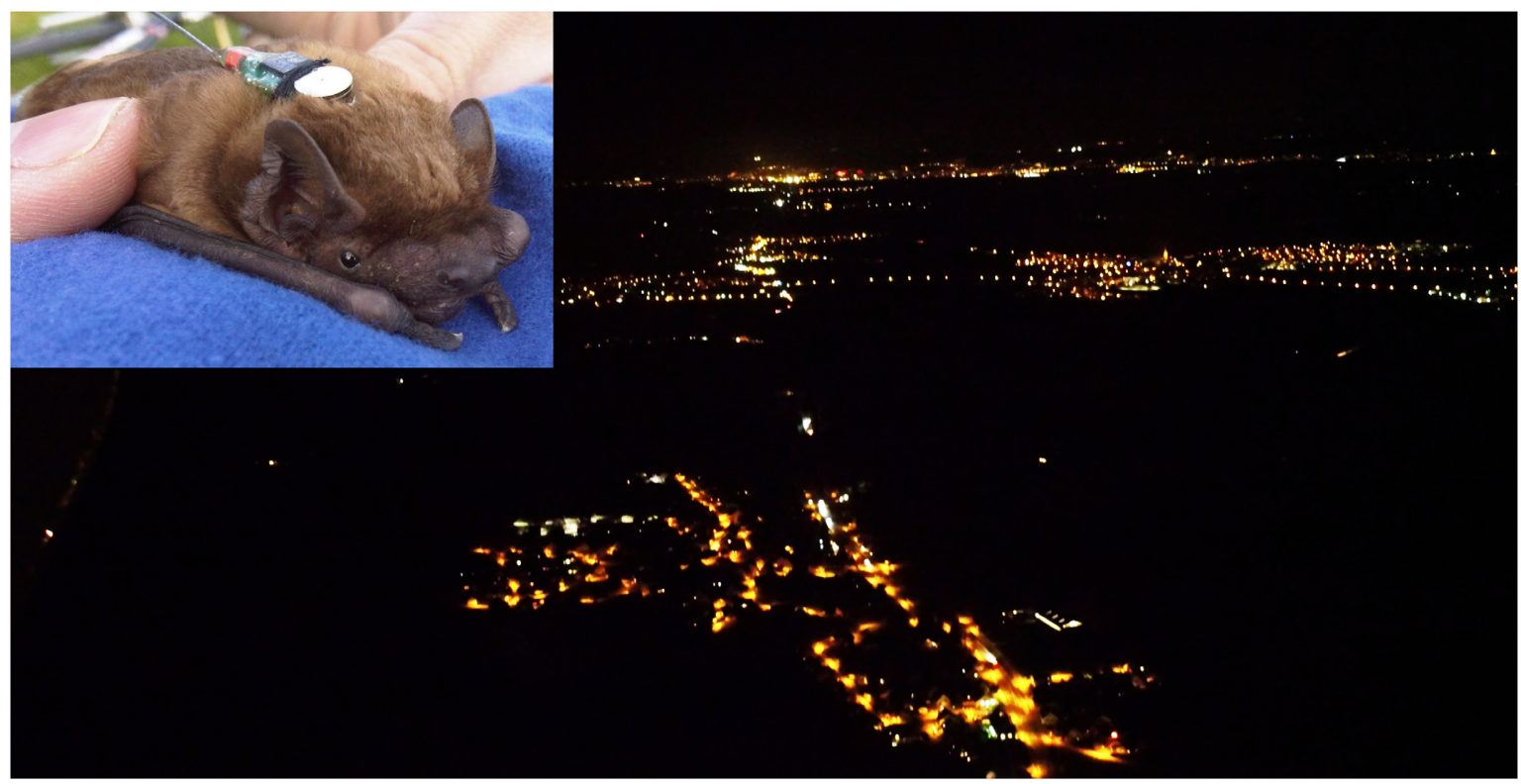

FIG. 1. A bat's perspective of the migration route showing the night lights moving northeast from Lake Constance. Inset: common noctule with a collar-mounted air pressure tag.

bat in a Cessna 172 airplane as soon as it left the foraging range, recording GPS positions and the transmitter signal (see O'Mara et al. 2019 for methods). From this we derived detailed three-dimensional representation of bat migration steps (Fig. 2). We extracted altitudes every $6 \mathrm{~s}$ and used a bilinear interpolation to match
GPS positions to altitudes (see Data Availability). We annotated these data with wind direction and speed using European Centre for Medium-Range Weather Forecasts data and topography from Advanced Spaceborne Thermal Emission and Reflection Radiometer Digital Elevation Model using Movebank Env-DATA.
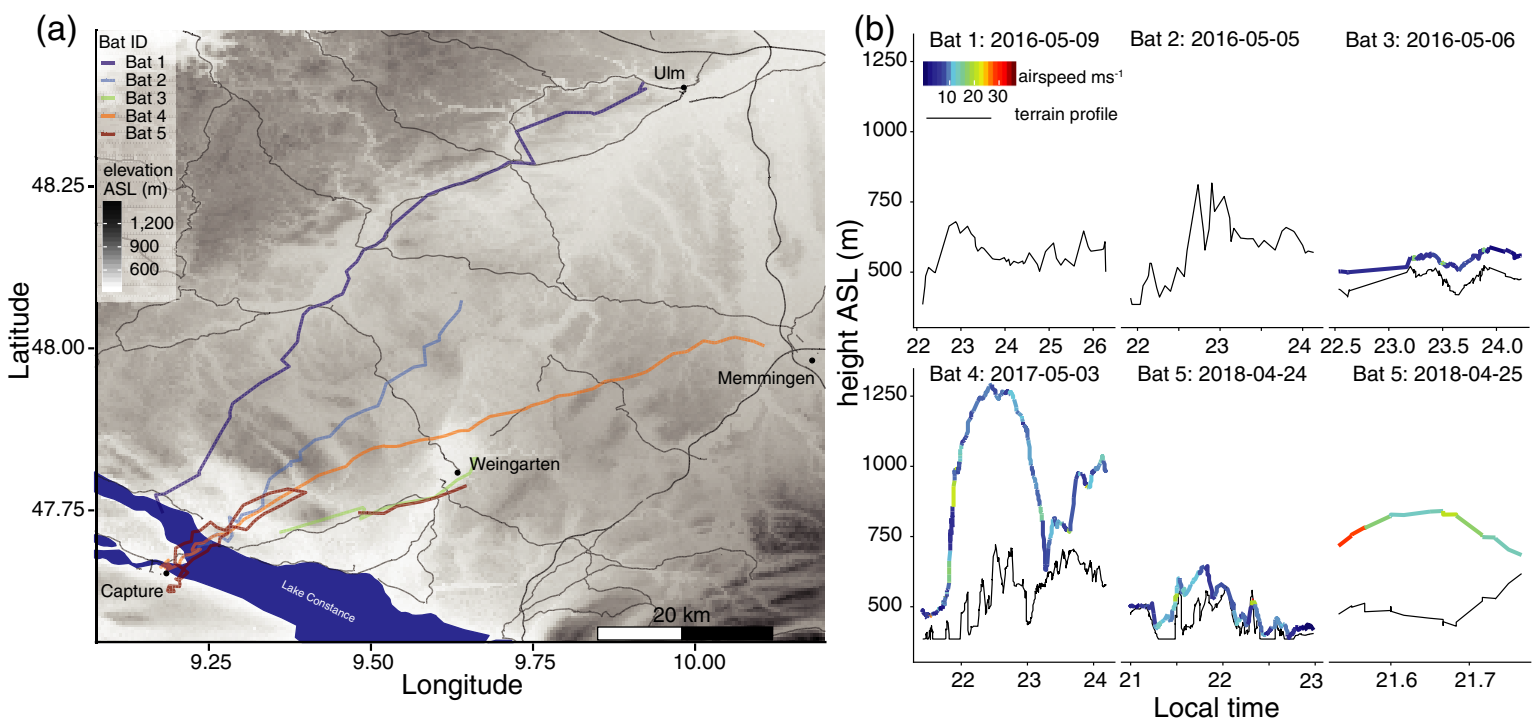

FIG. 2. Migration map (a) showing individual bat flights as they left our capture site in Switzerland (lower left) and topographic relief of the study area (397-1,494 m above sea level). (b) Individual altitude profiles colored by airspeed are plotted above the terrain profile of the ground level below. Bats 1 and 2 did not have altitude information, and the only the terrain is shown. All data are available (see Data Availability statement). 
We recorded a full migration step of five individuals, and we were able to assign altitude to three of these (two did not send air pressure data). Bat 5 turned around after flying $29.4 \mathrm{~km}$ (possibly because of an approaching cold front) and flew a 51.9-km return path to near the previous night's roost. This female migrated the next day, producing two dissimilar flight paths (Fig. 2a). Common noctules forage at low flight altitudes (Roeleke et al. 2018, O'Mara et al. 2019), but we expected migration altitudes within the $40-150 \mathrm{~m}$ above ground level (AGL) range of common wind turbine sweep areas, due to the large numbers of casualties at wind power plants (Voigt et al. 2012). We also expected a migration pattern like what is generally assumed for small songbirds, with ascent to altitude followed by more or less level flight.

Bats migrated in a northeasterly direction after foraging (between 9:00 and 9:30 p.m.). This was the only similarity among individuals that showed flexibility in their migratory altitudes, distances, and stopover sites. Bats caught from the same roost (Bats 1 and 2, Bats 3 and 4) did not migrate together, and these bats migrated over different distances $(45-117 \mathrm{~km})$, and stopped over at different sites (Fig. 2a). Accordingly, flight time also differed (1.7-4.1 h) and did not depend upon departure time, but only on distance covered. Mean airspeeds were $7.2-15.9 \mathrm{~m} \mathrm{~s}^{-1}$ (range: $0.45-35.6 \mathrm{~m} \mathrm{~s}^{-1}$ ), and mean ground speeds $6.7-18.6$ $\mathrm{m} \mathrm{s}^{-1}$ (range: $0.2-35.7 \mathrm{~m} \mathrm{~s}^{-1}$ ). Interestingly, many of the fastest airspeeds we observed occurred on ascending flights, and tended to occur with higher headwinds. Overall climb rates $\left(0.58 \pm 0.58 \mathrm{~m} \mathrm{~s}^{-1}\right)$ and climb rates to high elevations $\left(0.59 \pm 0.22 \mathrm{~m} \mathrm{~s}^{-1}\right)$ were faster than overall descent rates $\left(-0.42 \pm 0.23 \mathrm{~m} \mathrm{~s}^{-1}\right)$ and descent from higher elevations $(-0.39 \pm 0.23 \mathrm{~m}$ $\left.\mathrm{s}^{-1}\right)$. These are consistent with the foraging-altitude movement of common noctules (O'Mara et al. 2019). Bats typically migrated into low head winds (Dechmann et al. 2017). Only Bat 5 migrated with higher tail winds, and then flew into headwinds of $1.8 \mathrm{~m} \mathrm{~s}^{-1}$ when it turned around. It migrated again during the following night with fairly strong tailwinds $\left(2.9 \mathrm{~m} \mathrm{~s}^{-1}\right)$, flying at consistent airspeeds of $8-12 \mathrm{~m} \mathrm{~s}^{-1}$ during both nights. Most interesting were the unexpected altitudinal changes, which resembled those found in migrating thrushes (Bowlin et al. 2015). Some bats followed the landscape profile at fairly low altitudes (Bat 3: $69.06 \pm 17.88 \mathrm{~m}$ AGL, Bat 5 first night: $50.46 \pm 45.52 \mathrm{~m}$ AGL); others flew higher (Bat 4: $345.02 \pm 234.62 \mathrm{~m}$ AGL, Bat 5 second night: $294.96 \pm 84.25 \mathrm{~m}$ AGL). Only Bat 4 ascended to higher altitudes of $801 \mathrm{~m} \mathrm{AGL}$, but remained there briefly and soon began to descend toward its stopover site (Fig. 2b). The example of Bat 5 shows that individuals migrate flexibly, even over consecutive nights and the same terrain.
Individual migratory flights differed, both within and among individuals. This is similar to Swainson's thrushes, which show a large amount of variation in timing, duration, and altitude of individual tracks (Bowlin et al. 2015). This suggests that individuals make decisions to take advantage of wind, landscape, and navigational conditions or other, yet-unknown factors, to optimize their nightly flights. Our results once more confirm that the flexibility and behavioral repertoire of individuals in the wild are greater than we assume. More work is necessary to understand the threats and challenges common noctules and other migrating species encounter as they move across the landscape, particularly as over $40 \%$ of our observations were within the sweep range of most wind turbines in Germany.

\section{AcKNowledgments}

Our thanks go to the participants of the University of Konstanz course "Going Wild" 2018, Marion Muturi, Wolf-Dieter and Ursi Burkhard, Marius and Franziska Heeb, the Seeburgpark staff, Peter Bergsteiner (Stadtverwaltung Kreuzlingen) and two anonymous reviewers.

\section{Literature Cited}

Bishop, C. M. et al. 2015. The roller coaster flight strategy of bar-headed geese conserves energy during Himalayan migrations. Science 347:250-254.

Bowlin, M. S. et al. 2010. Grand challenges in migration biology. Integrative and Comparative Biology 50:261-279.

Bowlin, M. S. et al. 2015. Unexplained altitude changes in a migrating thrush: long-flight altitude data from radio-telemetry. Auk 132:808-816.

Dechmann, D. K. et al. 2014. Tracking post-hibernation behavior and early migration does not reveal the expected sex-differences in a "female-migrating" bat. PLoS ONE 9: e114810.

Dechmann, D. K. N., M. Wikelski, D. Ellis-Soto, K. Safi, and M. T. O'Mara. 2017. Determinants of spring migration departure decision in a bat. Biology Letters 13:20170395.

Häussler, T. F., and A. Nagel. 2003. Grosser Abendsegler Nyctalus noctula (Schreber, 1774). Pages 591-622 in M. Braun, and F. Dieterlen, editors. Die Sugertiere Baden-Wrttemberg. Ulmer (Eugen), Stuttgart.

Holland, R. A. 2007. Orientation and navigation in bats: known unknowns or unknown unknowns? Behavioral Ecology and Sociobiology 61:653-660.

Hutterer, R. 2005. Bat migrations in Europe: a review of banding data and literature. Vol. 28. Federal Agency for Nature Conservation, Bonn, Germany.

Krauel, J. J., and G. F. McCracken. 2013. Recent Advances in Bat Migration Research Pages 293-313 in R. A. Adams, and S. C. Pedersen, editors. Bat evolution ecology and conservation. Springer, New York, New York, USA.

McGuire, L. P., K. A. Jonasson, and C. G. Guglielmo. 2014. Bats on a budget: torpor-assisted migration saves time and energy. PLoS ONE 9:e115724.

O’Mara, M. T., M. Wikelski, and D. K. N. Dechmann. 2014. 50 years of bat tracking: device attachment and future directions. Methods in Ecology and Evolution 5:311-319. 
O’Mara, M. T., M. Wikelski, B. Kranstauber, and D. K. N Dechmann. 2019. Common noctules exploit low levels of the aerosphere. Royal Society Open Science 6:181942.

Roeleke, M., T. Teige, U. Hoffmeister, F. Klingler, and C. C. Voigt. 2018. Aerial-hawking bats adjust their use of space to the lunar cycle. Movement Ecology 6:11.

Voigt, C. C., A. G. Popa-Lisseanu, I. Niermann, and S. Kramer-Schadt. 2012. The catchment area of wind farms for European bats: a plea for international regulations. Biological Conservation 153:80-86.

Weller, T. J., K. T. Castle, F. Liechti, C. D. Hein, M. R. Schirmacher, and P. M. Cryan. 2016. First direct evidence of long- distance seasonal movements and hibernation in a migratory bat. Scientific Reports 6:34585.

\section{Data Availability}

Data are available on the Movebank Data Repository: https://doi.org/10.5441/001/1.5d736bf0 